\title{
FUTURE PROOF CONSTRUCTION WITH INNOVATIVE SUSTAINABLE BUILDING MATERIALS
}

\author{
Emilia Van Egmond \\ Netherlands Senior Experts, the Netherlands \\ E-mail: elcvanegmond@online.nl
}

\begin{abstract}
It is unquestionable that the construction performance needs to improve, despite its importance to the national economies. This industry is commonly, rather polluting, non-sustainable, with a low level of innovation compared to other sectors. Lessons from the past in other sectors indicate that a sequence of innovations pushed forward productivity and performance. Notwithstanding some innovative developments in the course of time, a widespread change of performance in construction is not many. The objective of this paper is to discuss strategies to enhance the development and use of innovative sustainable building materials in construction. It draws on empirical evidence and contemporary theoretic views regarding the factors impeding or stimulating innovation. These learn that innovations require strong collaboration amongst the construction players in the industry network to achieve sustainability in construction.
\end{abstract}

Keywords: construction, innovation, building materials, sustainability, collaboration, industry network.

\section{INTRODUCTION}

The construction industry is often blamed for being inefficient, non-sustainable, compared to other sectors, proves to be one of the largest industries and the activities are held responsible for a large contribution to pollution. The construction industry consumes large parts of the world's natural resources, which is 3 billion tons of raw materials annually and about $40 \% \mathrm{t}$ of total global use. (Roodman and Lenssen 1995). The sector's emission from fuel combustion was $2.4 \%$ of global carbon emissions in 1994 and around 5\% of global anthropogenic $\mathrm{CO}_{2}$ emissions when process emissions are added to this (OECD/IEA,2009). Moreover, the construction activities do not provide enough decent housing especially for young and lower income households in many countries.

In the following first lessons from the past regarding innovation in other sectors like manufacturing will be presented. Then innovation in the construction industry will be discussed. Some examples are given to illustrate the innovations in 
construction. A particular focus will be on innovative sustainable building materials that came into existence lately. Next, we will review the empirical evidence and contemporary theoretic views regarding the factors impeding or stimulating innovation. At last, we will discuss the implications of these views for strategic steps to be taken in the construction industry to push it towards innovativeness and improved sustainable performance.

\section{THEORY / RESEARCH METHODS}

\section{Innovation}

The innovation process is rather complex. The process implies efforts and interventions regarding the use and development of knowledge and skills that lead to the creation of adoption and use of new technologies. The various innovation activities include the search for existing new products and processes; the development and generation of technological products and processes; the execution of fundamental research; the transfer and implementation of the results in the market; the adaptation and improvement of (new) products and processes after implementation, use, and evaluation.

Man has gained more and more knowledge and skills in the course of time. Knowledge and technological innovations have been combined to enable the development of new innovative ideas and skills.

The process of innovation in many industrialized countries involved extensive changes in production systems which resulted in a shift from home-based manual production to large-scale factory production. Innovation and socio-economic development are closely intertwined, particularly regarding innovation in the field of large-scale energy production and of new materials such as metallurgy, plastics, and polymers, such as applied in industries. (Dicken, P, 2000) The production systems in manufacturing changed through innovations.

There are different forms of innovation: incremental, breakthrough and radical- or disruptive innovation. These forms are further explained below with examples from the manufacturing sector.

\section{Incremental Innovation}

The majority of innovations (around 70\%) in all industrial sectors is incremental innovation. Incremental innovation involves making small scale improvements to add or sustain value to existing products, services and processes. An example of incremental innovation comes from Coca-Cola. The brand's line extensions such as Cherry Coke, Coke with Lime and Coca-Cola Lite have enabled the already long existing brand to stay relevant and bring something new to its customers over the years. 


\section{Breakthrough and Radical Innovation}

In this type of innovation, the existing knowledge leads to creating new knowledge that is used for other innovations in related areas, which may cause a tremendous disruption, i.e. the impact on the environment and man which involves a change in living, doing, using, etc. There will be gaps to bridge required by the change.

Breakthrough innovation comes in two forms: new technology that relies on an existing business model or a new business model that utilizes existing technology.

An example of a new technology that relies on an existing business model is from Dyson. This company that was the world's first bagless vacuum cleaner producer is based on an existing business model but the company developed new technology to substantially improve the market offering. Another example of breakthrough innovation is the establishment of supermarkets which use a new business model. It caused in many cases the disappearance of small individual shops, like bakery-, butcher-, foodstuff-shops.

\section{Radical or Disruptive Innovation}

ICT development is a great example of radical innovation during the $20^{\text {th }}$ century. It has had a disruptive impact on many aspects of society. The introduction of personal computers in office environments is an example of disruptive innovation both in the field of technology as well as the business model. Secretarial work changed, letters are no longer dictated, fountain pens disappear from the desks.

Manufacturing enterprises like Nike and Siemens are heading for cyberphysical systems. The goal is to further develop 'digital enterprises' that can adapt to market conditions and use resources efficiently, thus produce more sustainable. That means using technology to integrate product and production lifecycle processes.

Hence looking back at the past in other sectors one can notice a sequence of innovations which pushed forward the productivity and performance. First by knowing more about materials to be used, then about energy use in production processes; after that knowledge increased about the processes themselves, the management and how to improve these. Next, in the era of ICT, tasks are taken over by computers and robots, to make fewer mistakes and produce faster. Now the stage has reached to reconsider material use at the nano level and the effects of these on the environment and its communities. Innovation has become more and more complex and relies on combinations of knowledge and skills of different disciplines and from different sources. (Egmond 2005, 2009) 


\section{RESULTS AND DISCUSSION}

\section{Innovation in Construction}

By drawing parallels between the impacts of innovations on the industrialization process in manufacturing, innovations in construction are also expected to contribute to reduce costs through faster construction, to increase construction quality and sustainability, to eliminate dependence on weather conditions at the construction site, and to improve coordination of planning and construction.

To improve construction towards future proof, more sustainable and productive performance innovations should be applied in each of these processes. Through innovation the design and engineering allow for flexibility, meeting fastchanging needs of customers; The construction process can be done speedily and in time.

In short: innovation in the construction industry that contributes to sustainability, refers to the use and development of knowledge and skills, through the search for and adoption of elsewhere developed knowledge and technologies, the execution of fundamental research; that lead to the creation of adoption and use of new technologies, products, and processes in the construction market, that have a positive effect on requirements of man, environment and economy.

Meanwhile, innovation took place in the construction industry - though limited compared to manufacturing- by using combinations of innovative solutions based on accumulated technological and knowledge advances in attempts to move from largely craft-based construction to a systematic construction process where resources are utilized efficiently.

\section{Examples of Innovative Design and Engineering for Sustainability}

A new business model in construction, the so-called Circular Model, is used by the European construction group Royal BAM in a pilot project, named "Circle" in collaboration with the interdisciplinary design studio Doepel-Strijkers, emphasizing reusability. Circular Business Models consider the entire lifecycle of a project. It is a basic design philosophy founded on the principles of the circular and inclusive economy. The project involves a large pavilion located on the lower floors of Dutch banking group ABN AMRO's headquarters in Amsterdam, intended for deconstruction from the outset. The idea is that modular building techniques and careful tracking of resources, from spatial design to material choice, should make it possible to reuse virtually all of Circle in other buildings. Thanks to multifunctional and movable furnishings, the interior can be adapted for a variety of functions including a daycare, performance venue, meetings, indoor market, exhibitions, or film screenings. The idea is that BAM is trying to create ways to lease materials so that this future value can be captured." To that end, BAM is developing an online marketplace to enable 100 percent reuse, as well as new contracting methods that will better account for reuse and contribute to sustainability. 


\section{Improved Sustainability Efficiency and Efficacy in Construction Processes}

At present artificial intelligence (AI) is starting to make headway into the construction industry. Construction processes are expected to change due to advances in the AI industry. Smart city planning, predictive modeling systems, and autonomous building trucks are the near future of the industry.

The Japanese heavy construction company Komatsu has been developing Augmented Reality (AR), a smart construction technology, which involves taking aerial photos of the site using drones and then transforming those images into 3D data for the site and sending them in real-time.

\section{Sustainable Innovative Building Materials \& Systems}

The construction industry is a great consumer of natural resources such as wood, minerals, water, and energy. Buildings consume $20-50 \%$ of the physical resources, according to their environment. The consciousness of this gave a boost to the search and use of environmentally-friendly materials, also known as green building materials, which have for their production, placing and maintaining a low environmental impact. Moreover, these materials are durable, reusable or recyclable, include recyclable materials in their composition and are from resources of the area close to where the building activity takes place. Some examples are described in the following.

\section{Coconut shells and fibers as a substitute for aggregates in developing concrete hollow blocks.}

Coconut shells and fibers are also applicable as a partial substitute as coarse aggregates for concrete hollow blocks. The quality of the coconut shell and fibers to be used as aggregate of concrete hollow blocks is determined by its particles, shape, and texture, resistance to crushing, absorption and surface moisture, grading, resistance to freezing and heating and lightweight. So far the coconut shells and fibers are classified as miscellaneous material, generally used for wall panels and partitions. A research project indicated that hollow blocks with Waste Coconut Shells as a Substitute for Aggregates in Mix Proportioning a compressive strength higher than the conventional concrete hollow blocks after 28th days. (Recycling of Waste Coconut Shells as Substitute for Aggregates in Mix Proportioning of $\begin{array}{llll}\text { Concrete Hollow } & \text { Blocks. } & \text { Available }\end{array}$ https://www.researchgate.net/publication/257099368)

\section{Agricultural Waste}

An example of an innovative use of agricultural waste is Cornspan in Chang Mai Thailand. Burning corn waste (corn husks and cobs) is a common farming practice in Chiang Mai, Northern Thailand. It is the cause of an annual haze effect, an atmospheric condition where particles, smoke, dust, and moisture suspend in the air, obscuring visibility and causing long term damage to both the environment and the 
health of those people who live within it. By aiming to reduce or eliminate the problem the Thai ApiladaVorchart (architect /designer/researcher with a multidisciplinary approach to projects concerning materials) developed economically attractive uses for the corn waste, with an emphasis on environmentally sustainable practices and traditional craft skills whilst providing the economic and social benefits for local families and communities. Corn husk fibers are used to manufacture panels that can be applied in local construction for sound and thermal insulation. Charcoal from corn cobs can be added to give it smell and moisture absorption qualities. These panels facilitate improved standards of habitation and provide additional income for local families whilst mitigating against the haze effect.

\section{Bio-Foam made from Algal Bloom}

Algae are one of the few species that thrive because of global warming, forming a problem of their own. Algae grow fast but only live for a short time before starting to decay, a process that consumes oxygen from the water. The severe eutrophication of coastal areas in maritime countries is one of the biggest environmental threats at present. Oxygen depletion, excessive nutrients supply, and eutrophication severely harm the functioning of marine ecosystems.

Indonesia, the Philippines, Australia, Japan, and the Baltic region, emphasize the global problem of the excessive blooming of Cladophora algae, not only from an ecological perspective. The detrimental impacts of this on society is not negligible. Shores, public beaches are covered thick dense biomass of deteriorating algae spreading a strong septic smell. Although filamentous green algae do not produce toxins in contrast to blue-green algae, the rotting algal biomass forms an excellent environment for bacterial growth, such as Salmonella, thereby putting human health at risk. Cleaning of the shores requires investment in time and money. Tourists stay away and real estate prices in coastal areas are dropping.

*A US-based company called Bloom found a way to harvest the algal bloom and turn it into bio-foam. By means of a mobile harvester unit the pond water with algae blooming is pumped up and mixed. with a water-safe coagulant that causes the algae to clump together. These flocks are skimmed off into a collection tank. The water with algae mass is filtered and the excess water is put back in the pond, after which the algae are dewatered and dried in a solar drying process. When the mass is dry, it is turned into flexible foam. The bio-foam is not biodegradable since it is combined with ethylene vinyl acetate (EVA) that enhances the performance qualities of the foam. Additionally, the foam has antimicrobial properties, which are solely derived from algae. This antimicrobial component is for $99.99 \%$ effective against the growth of odor-causing bacteria. All foams are also hypoallergenic. The foam is produced in a large variety of densities. Bloom is not the first to make products out of algae, nor is it the first bio-foam.

*Spiral Plate Technology (SPT)In the Netherlands Evodos (www.evodos.eu) developed a way to produce sustainable algae as well as a dehydration device: The Spiral Plate Technology (SPT) centrifuge for separating the 
algae in liquid and to convert it into bio-foam. The algae are dehydrated and dried by means of solar-drying, to become a flexible foam, with antimicrobial and hypoallergenic properties.

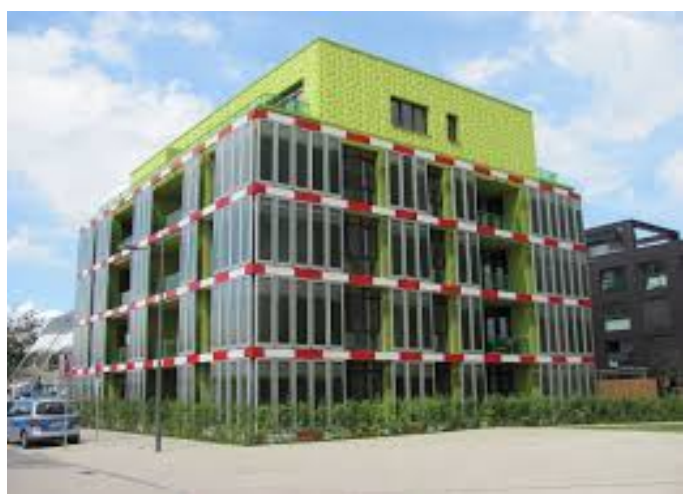

Figure 1. Bio Intelligent Quotient House (BIQ) Source: http://www.sacredheart.gy/history.php

*The BIQ Project (Figure 1). In Hamburg Germany Arup construction company along with SSC Strategic Science Consultants and Splitterwerk Architects designed a building called the Bio Intelligent Quotient House (BIQ). It contains 15 apartments and has 129 algae filled louvered tanks hanging on its exterior, on the south-east and south-west part of the building. The purpose is to power the building exclusively by algae, i.e. to heat buildings, fertilize rooftop gardens and even filter vehicle exhaust fumes. https://www.arup.com/en/projects/SolarLeaf

The algae were retrieved from the Elbe River and then placed in large, thin, rectangular cases. The algae live inside these clear cases in a water solution, provided with nutrients and carbon dioxide using an automated system. Each tank is fixed to the outside walls of the building, onto the scaffolding, thereby allowing the tanks to be turned towards the sun (a similar technology that is used by solar collectors).

After the algae in each tank have reached a certain age, some of the biomass is harvested and taken into a processing facility in the building, to convert it into biogas. This provides heat during the winter months.

\section{3d-Printed Concrete Buildings and Bridges}

Experiments are on-going on the use of ICT and 3-D opportunities to be used in the construction industry. Additive-manufacturing concrete printers aren't exactly new but still, research is done to find the most effective and efficient way of working with the new technology. The cement mixture to be used is one of the aspects to be investigated further.

In any case in China, for example, complete housing units are printed at present. In the Netherlands, Delft University alumni are in the course of printing a total canal house(based on the traditional design) in Amsterdam. 


\section{CONCLUSIONS}

There are many examples of innovative solutions, that have come into existence all over the world. Innovations could be developed, based on knowledge and skills that were already available somewhere and served the purpose to increase productivity and sustainability. Most innovations in the construction industry are incremental. What could be seen is that the cumulativeness of the technical advances reflects the existence of a technology and knowledge base? However, evidence learns that it takes time and often quite some barriers to overcome once the invention is developed.

To enhance the acceptation and adoption of the innovation, innovators must put efforts to communicate their invention, share their ideas with the public and invest in marketing.

The available array of innovations in the construction industry worldwide gives way to the idea that there is no need to invent the wheel all over again. No need for too many efforts for research to develop critical "next generation" innovations. It is possible to make use of new design concepts, building technologies, and products, which were developed elsewhere. By doing so it implies fewer risks, time, the money needed to bring about complete new inventions. Besides, there are excellent opportunities, thanks to ICT developments that might support free transfers of innovations.

Although there are incentives to innovate, still innovation does not always result in the expected effects of improved productivity and sustainability. There are factors impeding innovation and improved sustainability.

The technological regime, (the existing common culture or pattern of thinking, perception, behavior), seems to adversely affect the acceptation, adoption, and application.

Not all linkages are strong. Not everybody is always familiar with the available array of innovative solutions. Knowledge exchange is often insufficient. A negative aspect of the easy access to innovations that were developed elsewhere is the possible adoption of products and processes that are not appropriate in the local context. (Egmond 2007).

In short, can be stated that innovation can contribute to improved productivity and sustainability in Construction. However, one should take into account that the uptake, acquisition, adoption, and implementation of innovative solutions in the market is often impeded, but also sometimes stimulated by specific features of (1) the local economic and socio-organizational context;(2) particular client's requirements for sustainable construction; (3) regime, rules habits in the rather traditional construction industry.

Innovative designs, building technologies, and products should match with these features. Adoption and application of innovations requires in most cases (1)Willingness and capability to accept and apply (2) a proper merge of existing and new knowledge and skills; (3) change in traditional culture and habits amongst both clients and construction players; (4) collaboration and consensus amongst various 
players in the network of the construction industry: architects, engineers, contractors, material suppliers, research \& educational institutes, policymakers.

\section{RECOMMENDATIONS}

There are excellent opportunities to make use of innovations, new design concepts and building products and technologies developed elsewhere, supported by ICT developments (free transfers of innovations)

There are various players in the network of the construction industry, such as architects, engineers, contractors, material suppliers, research and educational institutes which form all together with the knowledge base of the industry. The many relations amongst them can support and stimulate the exchange of knowledge and skills, develop, identify, acquire, adapt, apply innovations.

A way forward to achieve the targets of sustainability could be through the development of integrated processes of design, construction, and management with transparent forms of planning and cooperation.

The foregoing leads to the conclusion that there are opportunities to enhance sustainability in construction through innovative building materials. However, Innovation for Sustainable Construction rests on the condition that strong collaboration amongst the construction players is required.

In this view it is recommended:

To establish and strengthen the relationship in Industry driven collaborative teams, beneficial for all partners, based on identified needs for innovation in the industry.

To develop, identify, adopt, adapt and apply cost-effective innovative sustainable strategies starting from the pre-design phase

To collaborate with research, educational institutes:

a. To carry out industry-driven scientific and engineering research

b. to develop "next generation" innovative sustainable design and engineering

c. to adapt acquired innovations from elsewhere with support from and

d. To exchange knowledge and skills, on the job and through demonstration projects

e. To merge existing and new knowledge and skills through training and education programmes for students and construction employees

f. Get support from and collaboration with policymakers and financing institutes

g. To enhance a regulatory and supporting framework to stimulate innovation in construction

h. To support financing opportunities

\section{REFERENCES}

Dicken, P. (2000) Global Shift: Reshaping the Global Economic Map in the 21st Century, London: Sage Publications Ltd. pages 656 
Egmond - de Wilde De Ligny, E.L.C. van, (2005). Successful Industrialization, Innovation, and Prefabrication in construction. Combining Forces. Advancing Facilities Management and Construction through Innovation (pp. 415-426). Helsinki, Finland: RIL, VTT

Egmond-de Wilde De Ligny, E.L.C. van (2006). Innovation and technology diffusion in construction by means of strategic niche management. In R. Pietroforte, E. de Angelis (Eds.), Construction in the XXI century: local and global challenges. Rome: EdizioneScientificheItaliane

Egmond-de Wilde De Ligny, E.L.C. van, Vulink, M.(2007) International technology and knowledge flows among foreign and local contractors, in Proceedings CIB World Building Congress, 2007, 14-18 May Cape Town, South Africa

Egmond-de Wilde de Ligny, E.L.C. van, (2009) Industrialisation Innovation and prefabrication in Construction, Working paper EvE/06-2008/BCC/TUe presented to OECD, Paris

Malerba F. (2002), Sectoral systems of innovation and production, Research Policy, 31, pp. 247-264

OECD/IEA (2009) World Energy Outlook 2008, OECD, Paris, http:/www.worldenergyoutlook.org/docs/weo2008/WEO2008.pdf

Roodman, D.M. and N. Lenssen, (1995), "A building revolution: how ecology and health concerns are transforming construction", Worldwatch Paper 124, Worldwatch Institute, Washington, DC, March. 